\title{
PROPRIEDADES QUÍMICAS DE UM LATOSSOLO AMARELO CULTIVADO COM PASTAGENS NA AMAZÔNIA ORIENTAL ${ }^{1}$
}

\author{
Walcilene Lacerda Matos Pereira²; Carlos Alberto Costa Veloso ${ }^{3 *}$; José Raimundo Natividade \\ Ferreira Gama ${ }^{3}$ \\ ${ }_{3}^{2}$ Pós-Graduanda do Depto. de Solos e Nutrição de Plantas - USP/ESALQ, C.P. 9 - CEP: 13418-900 - Piracicaba, SP. \\ ${ }^{3}$ Embrapa Amazônia Oriental, C.P. 48 - CEP: 66095-100 - Belém, PA. \\ *Autor correspondente <veloso@cpatv.embrapa.br>
}

RESUMO: A pesquisa foi conduzida com o objetivo de avaliar as modificações das propriedades químicas de um Latossolo Amarelo com cultivo de pastagens, submetidos a dois modelos de sistemas rotacionados, nos períodos chuvoso e seco, um com Brachiaria brizantha e o outro com Panicum maximum, nos anos de 1996 e 1997. O delineamento experimental utilizado foi em blocos casualizados, com os tratamentos dispostos num esquema de parcelas subdivididas, com doze repetições. As parcelas foram constituídas pelas forrageiras braquiarão e tobiatã e as subparcelas foram constituídas pelos períodos chuvoso e seco dentro de cada ano. Para o estudo das propriedades químicas do solo, foram coletadas amostras nos períodos chuvoso e seco. O material orgânico incorporado ao solo através de restos de vegetais e a presença de excremento animal alterou as propriedades químicas nos anos estudados. Os teores de $\mathrm{Ca}, \mathrm{Mg}, \mathrm{K}, \mathrm{P}, \mathrm{MO}$ e o valor de $\mathrm{pH}$ foram maiores no ano de 1997. Teores mais elevados de Ca e Mg foram obtidos no sistema de pastejo com tobiatã do que no sistema com braquiarão. No período chuvoso os teores de $\mathrm{Mg}, \mathrm{K}, \mathrm{MO}$ e o valor de $\mathrm{pH}$ foram maiores, com exceção de P e Ca para o ano de 1997.

Palavras-chave: sistema de pastejo, braquiarão, tobiatã, fertilidade do solo

\section{CHEMICAL PROPERTIES OF AN OXISOL OF EASTERN AMAZONIA UNDER PASTURE}

\begin{abstract}
In order to evaluate changes in chemical properties of a Xanthic Hapludox managed under pasture, using two rotational systems, this research was performed during the rainy and dry seasons, one with Brachiaria brizantha (system I) and other with Panicum maximum (system II), in 1996 and 1997. The experimental design was completely randomized, with treatments arranged in subdivided plots, considering periods as subplots within each year, and years as subplots within each forage. Twelve replicates were utilized, and data were collected during the rainy and dry seasons. The organic material, incorporated into the soil through vegetable and animal residues, influenced positivelly the chemical characteristics. Except for $\mathrm{Al}$, levels of $\mathrm{Ca}, \mathrm{Mg}, \mathrm{K}, \mathrm{P}, \mathrm{N}$, $\mathrm{C}, \mathrm{OM}$ and $\mathrm{pH}$ increased during 1997. Comparing both the Brachiaria brizantha and Panicum maximum system, the levels of nutrients increased in the rainy season, with the exception for $\mathrm{P}$ and $\mathrm{Ca}$.

Key words: Panicum maximum, Brachiaria brizantha, pasture system, soil fertility
\end{abstract}

\section{INTRODUÇÃO}

Nos últimos vinte anos a produção pecuária na região amazônica passou, de forma crescente, a ser desenvolvida em áreas originalmente de florestas. Cerca de cinco milhões de hectares destas áreas, estão localizadas principalmente ao longo das rodovias de integração, existente na região e foram transformadas em pastagens cultivadas (Veiga et al., 1985).

A cultura pioneira na região amazônica continua sendo as extensas pastagens (Serrão et al.,1979), com área estimada de 3,7 milhões de hectares cultivadas quase que exclusivamente com capim colonião (Panicum maximum) Esses autores estimaram que 20\% dessa área já se encontrava em estado de degradação.

O estabelecimento de pastagens cultivadas na região amazônica inclui, na maioria dos casos, derrubada da floresta, queima da biomassa vegetal e semeadura das forrageiras ou, em menor escala, o desbravamento da floresta por meios mecânicos, com o uso de trator e posterior semeadura.

Com a remoção da cobertura vegetal e a implantação de pastagens, tem ocorrido uma série de alterações nas propriedades químicas e físicas dos solos. Essas modificações podem ser de caráter positivo ou negativo, isto é, tanto podem provocar uma melhoria nas propriedades do solo como também podem acelerar sua degradação, dependendo principalmente da natureza do solo, da espécie vegetal, do sistema de manejo usado e do tempo de exploração agrícola.

A fertilidade natural da maioria dos solos amazônicos, diminui de forma acentuada quando é retirada sua cobertura vegetal e, portanto, torna-se necessário desenvolver sistemas agrícolas adequados que permitam 
melhorar sua recuperação, assim como, desenvolver e utilizar tecnologias direcionadas aos fatores de produção.

As alterações nas propriedades químicas do solo, após a retirada da mata natural e a introdução de novas culturas, dependem de vários fatores, como a classe de solo, a sua fertilidade inicial, o comportamento químico de cada nutriente, suas interações com o meio, a cultura introduzida, como também o manejo e os tratos culturais adotados.

Em Latossolo Amarelo da Amazônia Ocidental, Corrêa \& Reichardt (1995), identificando as alterações químicas do solo sob pastagem, em relação ao solo sob floresta, verificaram que o sistema de preparo das áreas para a implantação da pastagem melhorou a fertilidade do solo em relação à floresta. Entretanto, o desenvolvimento da pastagem foi afetado pelas deficiências de fósforo e nitrogênio no solo devido ao manejo inadequado.

Sob o ponto de vista prático e de interesse econômico, o estudo das alterações das propriedades do solo, induzidas pelo manejo, assume relevante importância na previsão dessas alterações, com a finalidade de se direcionar um sistema de manejo que vise a recuperação ou a manutenção do seu potencial agrícola (Fernandes, 1982).

Portanto, o objetivo deste trabalho foram avaliar as modificações nas propriedades químicas de um latossolo amarelo resultantes da implantação de pastagens de braquiarão e tobiatã submetidos a utilização de dois sistema rotacionado de manejo e verificar se essas propriedades foram alteradas por dois anos, nos períodos seco e chuvoso.

\section{MATERIAL E MÉTODOS}

A pesquisa foi conduzida nas dependências da EMBRAPA Amazônia Oriental, no período compreendido entre março de 1996 a setembro de 1997, no Campo Experimental "Dr. Felisberto Camargo", situado à margem direita do Rio Guamá, no município de Belém (PA), nas coordenadas $1^{\circ} 28^{\prime}$ de Latitude Sul e $48^{\circ} 27^{\prime}$ de Longitude Oeste de Greenwich, a uma altitude de $14 \mathrm{~m}$.

Segundo a classificação de Koppen, o clima local é do tipo Afi, com média do total pluviométrico anual de aproximadamente $2.870 \mathrm{~mm}$, com período chuvoso de dezembro a maio e seco de junho a novembro (Bastos et al., 1986). A temperatura média anual é de $26^{\circ} \mathrm{C}$, média das máximas de $31,3^{\circ} \mathrm{C}$ e médias das mínimas de $22,8^{\circ} \mathrm{C}$ e umidade relativa do ar de $85 \%$ (Bastos, 1972).

A vegetação primária característica da área é floresta equatorial perenifólia, apresentando alta heterogeneidade na composição de espécies dicotiledôneas de porte médio a alto, e grandes variações na densidade. O relevo local é plano, apresentando pequena variação altimétrica.

A vegetação da área, que era de floresta equatorial úmida, foi derrubada mecanicamente. Após a destoca, a área foi arada e gradeada a uma profundidade de $20 \mathrm{~cm}$ para o plantio das forrageiras nos meses de agosto a novembro de 1995. O solo da área experimental é classificado como Latossolo Amarelo álico, textura média, de acordo com EMBRAPA (1988). As características iniciais do solo $(0-20 \mathrm{~cm})$ antes do plantio das forrageiras eram: $\mathrm{pH}$ em $\mathrm{H}_{2} \mathrm{O}=4,9 ; \mathrm{Al}^{3+}=9,0 \mathrm{mmol}_{\mathrm{c}} \mathrm{dm}^{-3}$; $\mathrm{K}^{+}=0,5 \mathrm{mmol} \mathrm{dm}{ }^{-3} ; \mathrm{Ca}^{2+}=7,0 \mathrm{mmol}^{-3} ; \mathrm{Mg}^{2+}=3,9 \mathrm{mmol}$ $\mathrm{dm}^{-3} ; \mathrm{H}^{+}+\mathrm{Al}^{f_{+}^{+}}=81,0 \mathrm{mmol}_{\mathrm{c}} \mathrm{dm}^{-3} ; \mathrm{CTC}^{\mathrm{C}}=92,4 \mathrm{mmol}_{\mathrm{c}} \mathrm{dm}^{-3}$; $\mathrm{P}=6,0 \mathrm{mg} \mathrm{dm}^{-3}$; M.O.=36,0 $\mathrm{g} \mathrm{dm}^{-3} ; \mathrm{V}=12,34 \%$; argila $=160$ $\mathrm{g} \mathrm{kg}^{-1}$; silte $=40 \mathrm{~g} \mathrm{~kg}^{-1}$; areia grossa $=120 \mathrm{~g} \mathrm{~kg}^{-1}$ e areia fina $=680 \mathrm{~g} \mathrm{~kg}^{-1}$.

A coletas das amostras de solo para as análises químicas de fertilidade na profundidade de $0-20 \mathrm{~cm}$, foram efetuadas duas vezes ao ano, no período chuvoso (março) e seco (setembro). As amostras de solo foram secas ao ar, destorroadas e passadas em peneiras com malhas de abertura de $2 \mathrm{~mm}$. Na fração menor que $2 \mathrm{~mm}$, que constitui a terra fina seca ao ar (TFSA).

As análises químicas e físicas foram realizadas de acordo com EMBRAPA (1979), constando das seguintes determinações: $\mathrm{pH}$ (água), $\mathrm{P}$ (Mehlich-1), $\mathrm{K}, \mathrm{Ca}, \mathrm{Ca}+\mathrm{Mg}$, $\mathrm{Al}, \mathrm{H}+\mathrm{Al}$, matéria orgânica e granulometria.

O experimento foi conduzido com capim braquiarão e com capim tobiatã em um método rotacionado de pastejo com dois sistemas de manejo:

\section{Sistema 1}

A área neste sistema ( 7,2 ha), foi dividida em 12 piquetes de 0,6 ha cada, plantada a lanço, com o capim braquiarão (Brachiaria brizantha Hochst Stapf. cv. Marandu). A adubação de formação foi realizada na base de $270 \mathrm{~kg} \mathrm{ha}^{-1}$ de $\mathrm{P}_{2} \mathrm{O}_{5}, 50 \mathrm{~kg} \mathrm{ha}^{-1}$ de $\mathrm{N}$ e $65 \mathrm{~kg} \mathrm{ha}^{-1} \mathrm{de}$ $\mathrm{K}_{2} \mathrm{O}$. A adubação de manutenção constou de $200 \mathrm{~kg} \mathrm{ha}^{-1}$ ano-1 de $\mathrm{P}_{2} \mathrm{O}_{5}$ em uma única aplicação (janeiro) e $50 \mathrm{~kg}$ $\mathrm{ha}^{-1}$ de $\mathrm{N} \mathrm{e} 50 \mathrm{~kg} \mathrm{ha}^{-1}$ de $\mathrm{K}_{2} \mathrm{O}$ parcelada em três aplicações (janeiro, maio e agosto). Foram utilizados 33 novilhos da raça nelore, com idade inicial de 15 meses. O sistema de pastejo foi definido como sendo o período de ocupação de 3 e descanso 33 dias, respectivamente.

\section{Sistema 2}

Este sistema, foi plantado a lanço, com o capim tobiatã (Panicum maximum cv. Tobiatã), em uma área com 7,8 ha dividida em 6 piquetes de 1,3 ha cada. A adubação de formação foi realizada com $333 \mathrm{~kg} \mathrm{ha}^{-1}$ de $\mathrm{P}_{2} \mathrm{O}_{5}, 58,5$ $\mathrm{kg} \mathrm{ha}^{-1}$ de $\mathrm{N}$ e $75 \mathrm{~kg} \mathrm{ha}^{-1}$ de $\mathrm{K}_{2} \mathrm{O}$. A adubação de manutenção constou de $300 \mathrm{~kg} \mathrm{ha}^{-1}$ ano-1 de $\mathrm{P}_{2} \mathrm{O}_{5}$ em aplicação única (janeiro) e $50 \mathrm{~kg} \mathrm{ha}^{-1}$ de $\mathrm{N}$ e $50 \mathrm{~kg}^{2} \mathrm{ha}^{-1}$ de $\mathrm{K}_{2} \mathrm{O}$ parcelada em três aplicações (janeiro, maio e agosto). Foram utilizadas 28 novilhas bubalinas mestiças Murrah $X$ Mediterrâneo, com idade inicial de 18 meses. O sistema de pastejo foi definido como sendo o período de ocupação de 4 e de descanso 20 dias, respectivamente.

Os animais foram colocados nas áreas após o estabelecimento das pastagens récem-implantadas. Os mesmos, receberam no cocho, durante o período do experimento, sal mineral constituído de fosfato bicálcico, cloreto 
de sódio, sulfato de cobalto, sulfato de cobre, sulfato de magnésio, sulfato de zinco, sulfato de ferro, sulfato de manganês, iodato de cálcio, enxofre ventilado e selenito de sódio.

O delineamento experimental utilizado foi em blocos casualizados, com os tratamentos dispostos num esquema de parcelas subdivididas, com doze repetições. As parcelas foram constituídas pelas forrageiras braquiarão e tobiatã e as subparcelas foram constituídas pelos períodos chuvoso e seco dentro de cada ano. Para o estudo das propriedades químicas do solo foram coletadas amostras nos períodos chuvoso e seco.

Os dados do experimento foram submetidos à análise de variância segundo Gomes (1987), sendo as médias comparadas através do teste de "F" a $5 \%$.

\section{RESULTADOS E DISCUSSÃO}

Verificaram-se significativas modificações nas propriedades químicas estudadas, provavelmente provocadas por incorporação dos restos vegetais da vegetação existente na área.

\section{Matéria Orgânica}

O teor de matéria orgânica no solo variou nos períodos e anos, não havendo interações significativas. No que se refere aos sistemas estudados, não houveram diferenças significativas para este parâmetro.

Houve acréscimo substancial de matéria orgânica no solo para o ano de 1997, assim como aumento no conteúdo no solo no período chuvoso (Figura 1).

Houve incremento, no solo, de matéria orgânica para o ano de 1997, provavelmente em razão de certos componentes que constituem o material orgânico apresentarem resistência à decomposição, ocasionando acúmulo destes ao solo, pois a matéria orgânica é um componente dinâmico em constante renovação (Figura 1). O aumento do teor de matéria orgânica neste solo devese provavelmente a um maior suprimento de água em decorrência do período chuvoso, o que proporcionou melhores condições para o desenvolvimento das forrageiras, por consequência, um acréscimo na quantidade de matéria orgânica no solo, que possivelmente foi devido a redução de atividades dos microrganismos decompositores, ocasionando assim, um decréscimo em sua taxa de decomposição.

O processo de decomposição da matéria orgânica no solo ocorre com maior intensidade nos períodos em que a temperatura do solo é maior, pois temperaturas relativamente altas favorecem o processo de decomposição, ocorrendo uma redução no acúmulo de matéria orgânica no solo. Em geral, a decomposição da matéria orgânica é mais acelerada em climas quentes enquanto a regra é sequência mais lenta em regiões frias (Brady, 1989).

Conceição (1989) menciona que o maior conteúdo de matéria orgânica no solo parece estar relacionado com a forma de utilização agrícola dos solos e possivelmente com a estabilização da matéria orgânica pelos colóides do solo associados aos íons e, nos horizontes que possuem os maiores teores de material orgânico, retêm mais água que os demais.

\section{Potássio}

O potássio apresentou em seus teores diferenças significativas, no que se refere ao ano e período (Figura 2), mas de modo independentes, ou seja, não houve interação entre estes fatores.

A disponibilidade do potássio no período chuvoso é maior que no período seco, devido as adubações com fósforo e potássio realizadas nos meses de janeiro e maio, pois a adubação, além de aumentar diretamente o nível de potássio no solo, acrescenta fósforo que acarreta um aumento considerável de adsorção de fósforo (Figura 2). Outro fator importante relaciona-se com a menor taxa da mineralização da matéria orgânica neste período, obtendo, como consequência, um maior acúmulo de material orgânico, que além de contribuir com o potássio, aumenta a retenção deste elemento reduzindo as perdas por lixiviação.

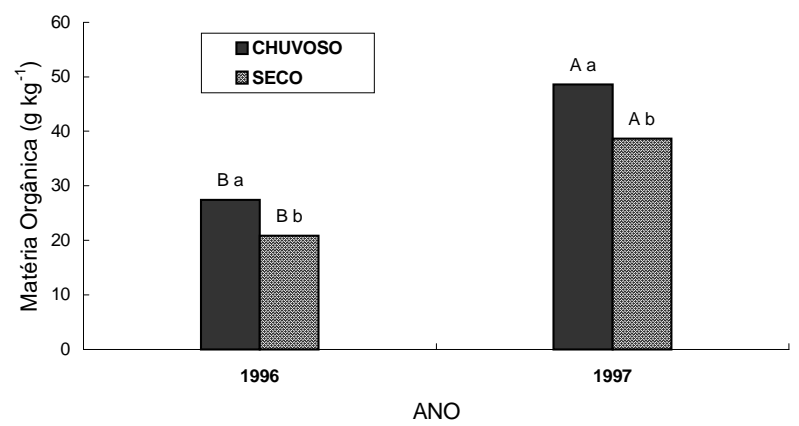

Figura 1 - Teores de matéria orgânica em amostras de Latossolo Amarelo em função dos períodos e anos. Média de doze repetições. Médias seguidas pela mesma letra maiúscula entre anos dentro do mesmo período e minúscula entre período dentro do mesmo ano, não diferem a $5 \%$, pelo teste $\mathrm{F}$.

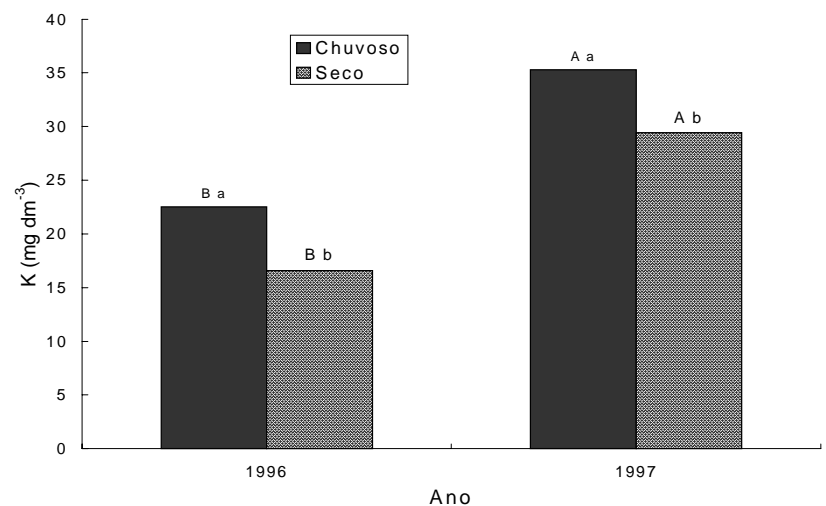

Figura 2 - Teores de potássio em amostra de Latossolo Amarelo em função dosanos e períodos chuvoso e seco. Média de doze repetições. Médias seguidas pela mesma letra maiúscula entre anos dentro do mesmo período e minúscula entre período dentro do mesmo ano, diferem a $5 \%$, pelo teste $\mathrm{F}$. 
O material de origem do solo é um dos meio de adição do $\mathrm{K}$ no solo. A elevação do teor de potássio no solo pode ser alterada somente através da aplicação de fertilizantes minerais e orgânicos (Braga, 1996). A concentração no tecido vegetal deste elemento no período chuvoso nas pastagens de Panicum maximum é de $1,15 \%$, enquanto para o período seco este valor decresce para $0,80 \%$ (Salinas \& Garcia, 1985). Fato semelhante ocorre para a Brachiaria brizantha cuja concentração é de $0,82 \%$ no período chuvoso, sendo quase o dobro do valor encontrado para o período seco que é de $0,44 \%$.

Foram observados acréscimos nos teores de potássio para o ano de 1997 (Figura 2), pois acredita-se que este aumento foi provocado pelo maior teor de matéria orgânica no solo, como verificado na Figura 1, ciclagem do nutriente nos sistemas e adubações realizadas.

O estudo do potássio em solo de pastagem, mostrou que os animais ingerem todo o potássio da gramínea. De $51,33 \mathrm{~kg} \mathrm{ha}^{-1}$ ano $^{-1}$ de $\mathrm{K}$ consumidos pelos animais somente $0,86 \%$ ficou incorporado aos tecidos dos animais, sendo a maior parte $(99,14 \%)$, reciclado ao pasto através da urina e fezes (Teixeira,1987).

A aplicação de esterco de bovino ao solo por 3 anos consecutivos, causaram aumentos duradouros de $\mathrm{pH}$ do solo, acompanhados da elevação dos teores de potássio no solo (Novais et al.,1996). Resultados semelhantes obteve Demétrio (1988), com altos teores de potássio com a adição de materiais orgânicos ao solo.

\section{Cálcio e Magnésio}

O cálcio e o magnésio apresentaram diferenças significativas para a interação entre períodos, sistemas e anos de experimento (TABELA 1). O cálcio e o magnésio, nos períodos chuvoso e seco, não apresentaram interações significativas entre si, para o ano de 1996 no sistema. No sistema II, o cálcio e o magnésio

TABELA 1 - Teores de cálcio e magnésio em amostras de Latossolo Amarelo em função dos anos, períodos e sistemas. Médias de doze repetições.

\begin{tabular}{|c|c|c|c|c|}
\hline \multirow[t]{2}{*}{ Elemento } & \multirow[t]{2}{*}{ Ano } & \multirow[t]{2}{*}{ Período } & \multicolumn{2}{|c|}{ Sistemas } \\
\hline & & & $\begin{array}{c}\text { I } \\
\text { (Braquiarão) }\end{array}$ & $\begin{array}{c}\|\| \\
\text { (Tobiatã) }\end{array}$ \\
\hline & & & -------- mmol & $\mathrm{dm}^{-3}$ \\
\hline \multirow[t]{2}{*}{$\mathrm{Ca}$} & 1996 & Chuvoso & $4,33 \mathrm{aB} 1$ & 11,33 aA 1 \\
\hline & & Seco & 2,25 aA 2 & 1,92 bA 2 \\
\hline \multirow[t]{2}{*}{$\mathrm{Ca}$} & 1997 & Chuvoso & 4,83 bB 1 & $12,00 \mathrm{bA} 1$ \\
\hline & & Seco & 9,33 aB 1 & 18,08 aA 1 \\
\hline \multirow[t]{2}{*}{$\mathrm{Mg}$} & 1996 & Chuvoso & $2,33 \mathrm{aB} 1$ & 6,42 aA 1 \\
\hline & & Seco & 1,25 aA 1 & 1,17 bA 2 \\
\hline \multirow[t]{2}{*}{$\mathrm{Mg}$} & 1997 & Chuvoso & 2,67 aB 1 & 6,92 aA 1 \\
\hline & & Seco & 2,42 aB 1 & 6,92 aA 1 \\
\hline
\end{tabular}

Médias seguidas pela mesma letra minúscula nas colunas e maiúscula nas linhas não apresentam diferença significativas a $5 \%$, pelo teste $\mathrm{F}$. apresentaram diferenças significativas, de modo semelhante com valores superiores durante o período chuvoso, sugerindo-se que seja devido as adubações realizadas neste período e ao maior acúmulo de matéria orgânica no solo. Quanto maior o teor de matéria orgânica no solo, maior quantidade de cálcio que pode ser retido em seu complexo, fato que possivelmente interferiu nos resultados acima.

Os teores de cálcio, em 1997, nos sistema I e II, durante o período seco sempre foram mais elevados apresentando-se com diferenças significativas. Provavelmente estes resultados se devem a taxa de mineralização da matéria orgânica, que é mais acentuada neste período, provocando com isso a liberação de nutrientes no solo, entre eles, o cálcio e em menor quantidade o magnésio. Contudo, o nutriente magnésio, não apresentou variações estatisticamente diferenciadas, entre os períodos, neste mesmo ano, nos sistemas I e II respectivamente.

No período seco, no ano de 1996, o cálcio e o magnésio não apresentaram diferenças significativas, entre os sistemas I e II no entanto, essa diferença foi observada no período chuvoso onde o sistema II superou os resultados obtidos no sistema I. Estes resultados, são atribuídos ao fato das concentrações desses nutrientes serem elevadas nos tecidos da gramínea plantada no sistema II. De maneira que a concentração de cálcio no tecido do Panicum maximum no período chuvoso foi de $0,60 \%$, enquanto que no Brachiaria brizantha apresenta-se com teor de 0,37\% (Salinas \& Garcia, 1985). Como foi observado anteriormente neste período ocorre maior acúmulo de material orgânico. A adubação utilizada no sistema II favoreceu a elevação dos teores de nutrientes encontrados neste solo, devendo levar-se em consideração a quantidade ingerida via sal pelo animal e o que foi reciclado ao solo.

O sistema II para o ano de 1997, em ambos períodos os resultados foram superiores aos obtidos para o sistema I, referente aos teores de cálcio e magnésio. Portanto, os valores de cálcio e magnésio obtiveram comportamento semelhantes.

O cálcio , para a interação entre os anos de 1996 e 1997, no período chuvoso e nos sistemas I e II não apresentou diferenças significativas, pois os sistemas apresentaram-se de modo semelhante (TABELA 1). No entanto, entre os anos de 1996 e 1997, no período seco e nos sistemas estudados, o mesmo nutriente obteve teor significativamente superior para o ano de 1997.

Quanto ao magnésio verifica-se que na interação entre os anos 1996 e 1997, no sistema I em ambos períodos não apresentou resultados significativos. No entanto, para o sistema II, esta interação entre os anos 1996 e 1997 e períodos estudados (chuvoso e seco) apresentou-se de modo significativo somente para o período seco. Estes resultados que são explicados possivelmente pelas mesmas razões citadas anteriormente, quando comentados os períodos e sistemas estudados. Portanto, não se 
deve deixar de ressaltar que diversas razões devem ser levadas em consideração tais como: a quantidade de adubos incorporados ao solo; manejo diferenciado nos sistemas; número de animais em pastejo; excrementos e restos de vegetais depositados no solo que contribuem para o aumento no teor dos nutrientes; ciclagem dos nutrientes e atividade de microrganismos.

Em estudos realizados pelo CIAT (1985), avaliando a quantidade de nutrientes encontrados nos detritos em pastagens sob pastejo, foi possível observar que existe um substancial retorno do $\mathrm{Ca}$ e $\mathrm{N}$, seguido do $\mathrm{K}, \mathrm{Mg}, \mathrm{S}$ e P. Relata ainda, que as concentrações dos nutrientes no período de menor precipitação pluviométricas aumenta a disponibilidade dos nutrientes.

O balanço do cálcio em área de pastagem, mostra que os animais ingerem mais cálcio do sal mineral do que da gramínea. De um total de $15,95 \mathrm{~kg} \mathrm{ha}^{-1}$ ano $^{-1}$ de cálcio consumido, $59,75 \%$ foi proveniente do sal mineral e o restante $40,25 \%$ foi da gramínea. O animal armazena somente 3,30 $\mathrm{kg} \mathrm{ha}^{-1}$ ano $^{-1}$ que corresponde a $20,69 \%$ do total ingerido e retorna ao pasto $79,31 \%$ (Teixeira,1987). O mesmo autor , relata que o ciclo de magnésio, permite um consu-mo total de $6,89 \mathrm{~kg} \mathrm{ha}^{-1}$ ano $^{-1}$, sendo $4,64 \%$ do sal mineral e a maior parte $(95,36 \%)$ da gramínea. Ficando retido nos animais 0,10 $\mathrm{kg} \mathrm{ha}^{-1} \mathrm{ano}^{-1}$, correspondente a $1,45 \%$ do total ingerido e retornando ao pasto cerca de $98,55 \%$.

\section{Fósforo}

O fósforo apresentou resultados significativos apenas para a interação entre ano e período, não diferindo estatisticamente para os sistemas analisados. A análise de variância demonstrou que foi significativa a interação entre ano e período para os teores de fósforo (Figura 3).

No ano de 1996 não houve diferença significativa entre os períodos seco e chuvoso. Para o ano de 1997, o período seco superou os resultados encontrados no período chuvoso. Dessa maneira, sugere-se que esta diferença seja ocasionada pela maior taxa de mineralização da matéria orgânica liberando nutrientes para o solo em maiores quantidades. Sendo assim este

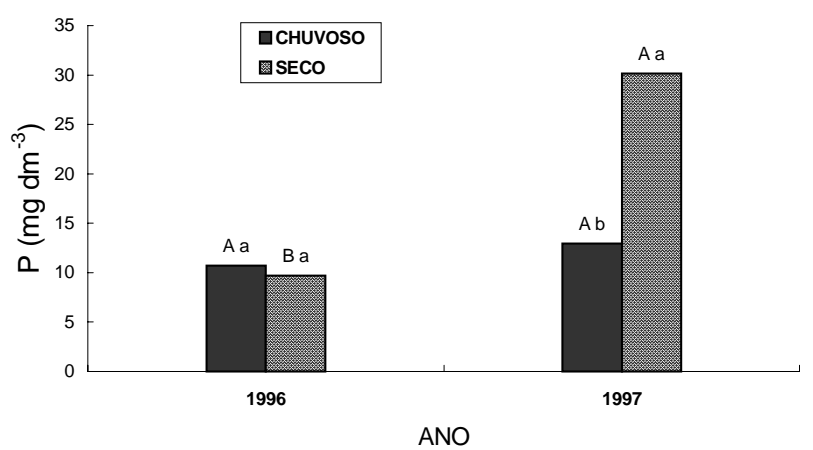

Figura 3 - Teores de fósforo em amostras de Latossolo Amarelo em função dos anos e períodos chuvoso e seco. Média de doze repetições. Médias seguidas pela mesma letra maiúscula entre anos dentro de um mesmo período e minúscula entre período dentro de um mesmo ano, não diferem a $5 \%$, pelo teste $\mathrm{F}$. aumento possivelmente esteja associado à aplicação de adubos fosfatados, ao manejo das pastagens, onde os animais recebem porções consideráveis de fósforo via sal mineral e grande parte deste é retornado ao solo através das fezes e urina.

$\mathrm{Na}$ interação entre os anos de 1996 e 1997, no período chuvoso o teor de fósforo não diferiu estatisticamente, mas para o ano de 1997, no período seco, o fósforo apresentou valores superiores, o que parece ser resultante da aplicação de adubos fosfatados e do maior conteúdo de material orgânico no solo, neste ano (Figura 3). Resultados semelhantes a estes foram obtidos pelo CIAT (1985), avaliando a quantidade de nutrientes encontrados nos detritos em pastagens sob pastejo.

A disponibilidade de fósforo no solo é aumentada pela matéria orgânica decomposta, já que certos compostos orgânicos formam complexos com ferro e alumínio evitando a formação de compostos insolúveis de fósforo com esses dois elementos. A decomposição da matéria orgânica também produz ácidos inorgânicos, que dissolvem compostos de fósforo encontrados em formas insolúveis na solução do solo (Coelho \& Verlengia, 1973).

Os resultados obtidos para o fósforo neste experimento concordam com os de Demétrio (1988), em que o fósforo do solo apresentou os maiores acréscimos, nas doses de esterco de bovino, em relação ao feijão-bravo e colonião. Esses resultados são previsíveis em função do elevado teores de fósforo no esterco, devido a alimentação dos animais com suplementação mineral baseada em fósforo.

Os animais em pastejo ingerem mais fósforo do sal mineral do que das gramíneas. Em um total de 5,93 $\mathrm{kg} \mathrm{ha}^{-1}$ ano ${ }^{-1}$ de fósforo consumido, $60,88 \%$ foi do sal mineral e somente $39,12 \%$ foi da gramínea. Do total ingerido, o animal armazena $31,53 \%$ e retorna ao pasto a maior parte, cerca de $68,47 \%$ (Teixeira,1987).

\section{Alumínio}

Os teores de alumínio no solo não apresentaram diferenças significativas para sistema e período, apenas nas observações referentes a 1996/97 (Figura 4).

Os valores mais baixos de alumínio no ano de 1997, são proporcionais a elevação do valor de $\mathrm{pH}$ no solo, onde a neutralização deste elemento decorre dos teores de cálcio e magnésio no solo.

O teor de alumínio mostrou-se com efeitos que divergiram sobre a adsorção do cálcio e magnésio pelos compostos orgânicos. Costa (1983), em experimentos realizados para verificar o efeito dos diferentes níveis de matéria orgânica em alguns atributos do solo, afirma que a incorporação de resíduos orgânicos no solo provocou diminuição nos teores de alumínio trocável.

A solubilidade do alumínio diminui com o aumento de $\mathrm{pH}$. Para os valores de $\mathrm{pH}$ acima de 5,5 - 6,0 (até 8,0), a solubilidade do Al é mínima. O nível de alumínio na solução do solo depende do $\mathrm{pH}$ do solo, da saturação do alumínio, do teor de matéria orgânica e da presença de outros íons na solução do solo (Alvarez et al., 1996). 


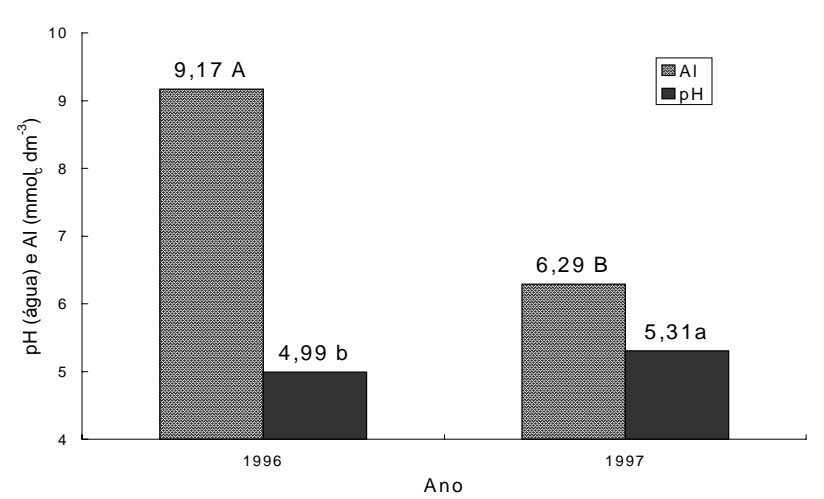

Figura 4 Teores de alumínio e valores de pH (em água) em amostras deLatossolo Amarelo em função dos anos. Média de doze repetições. Médias seguidas pela mesma letra maiúscula entre anos para os teores de alumínio e minúscula entre anos para os valores de $\mathrm{pH}$, não diferem a $5 \%$, pelo teste $\mathrm{F}$.

$\mathrm{pH}$

Os valores do $\mathrm{pH}$ não apresentam diferenças significativas nas variações de sistema e período, apenas nas observações referentes aos anos de estudo (Figura 4). No ano de 1997 houve acréscimo no valor de pH. Provavelmente este fato seja proveniente do efeito positivo da mineralização da matéria orgânica no solo, que auxilia no incremento da capacidade de troca catiônica (CTC) e soma de bases, causando assim, a maior liberação de cátions e ânions trocáveis que são adsorvidos pelos colóides do solo.

Do mesmo modo, estudos efetuados por Alfaia (1988) confirmam os resultados obtidos, em que houve aumento da CTC através da deposição de materiais orgânicos na camada superficial do solo, a qual, está diretamente relacionadas com $0 \mathrm{pH}$ do meio e principalmente com o teor de carbono orgânico existente no solo.

A CTC sofre aumento com a elevação do teor de matéria orgânica, conferindo ao solo maior adsorção de cátions trocáveis liberados pela decomposição da matéria orgânica (Costa,1983). E como consequência da elevação da CTC e dos cátions trocáveis, verifica-se aumento de saturação de bases o que causa, a elevação do $\mathrm{pH}$ e diminuição do alumínio trocável.

A matéria orgânica constitui-se de materiais que apresentam CTC tipicamente dependente de pH (Ribeiro et al., 1996).

\section{CONCLUSÕES}

- Material orgânico incorporado ao solo por meio de restos de vegetais e a presença de excremento animal alteraram as propriedades químicas nos anos estudados.

- Os teores de $\mathrm{Ca}, \mathrm{Mg}, \mathrm{K}, \mathrm{P}, \mathrm{MO}$ e o valor de $\mathrm{pH}$ foram maiores no ano de 1997.

- Teores mais elevados de $\mathrm{Ca}$ e Mg foram obtidos no sistema de pastejo com tobiatã do que no sistema com braquiarão.
- No período chuvoso os teores de $\mathrm{Mg}, \mathrm{K}, \mathrm{MO}$ e o valor de $\mathrm{pH}$ foram maiores, com exceção de $\mathrm{P}$ e Ca para o ano de 1997.

\section{REFERÊNCIAS BIBLIOGRÁFICAS}

ALFAIA, S.S. Correlação entre a capacidade de troca de cátions e outras propriedades de três solos da Amazônia central. Acta Amazônica, v.18, p.3-11, 1988.

ALVAREZ, V.H.; MELLO, J.W.V.; DIAS, L. E. Acidez e calagem do solo. In: FERTILIDADE e manejo do solo. Brasília: ABEAS, 1996. 67p. (Módulo, 4).

BASTOS, T.X. O estado atual dos conhecimentos das condições climáticas da Amazônia brasileira. Belém: IPEAN, 1972. p.68-122. (Boletim Técnico, 54).

BASTOS, T.X.; CHAIB FILHO, H.; MUNIS, T.D. de A.S.; LOBATO, V.H. de B. Flutuação das chuvas na região de Belém em distintos intervalos de tempo, período 1967-1983. In: SIMPÓSIO DO TRÓPICO ÚMIDO, 1., Belém, 1984. Anais. Belém: EMBRAPA, CPATU, 1986. v.1, p.37-43. (Documentos, 36).

BRADY, N.C. Natureza e propriedade dos solos. 7.ed. Rio de Janeiro: Freitas Bastos, 1989. 878p.

BRAGA,J.M. Potássio. In: FERTILIDADE e manejo do solo. Brasília: ABEAS, 1996. 62p. (Módulo, 8).

CENTRO INTERNACIONAL DE AGRICULTURA TROPICAL. Programa de pastos tropicales: informe anual. Cali: CIAT, 1985. 279p.

COELHO, F.S.; VERLENGIA, F. Fertilidade do solo. São Paulo: ICEA, 1973. 384p.

CONCEIÇÃO, M. Natureza do húmus e caracterização de solos com elevado teor de matéria orgânica da região de Itaguaí Santa Cruz, RJ. Itaguaí, 1989. 169p. Dissertação (Mestrado) - Universidade Federal Rural do Rio de Janeiro.

CÔRREA, J.C.; REICHARDT, K. Efeito do tempo de uso das pastagens sobre as propriedades de um latossolo amarelo da Amazônia Central. Pesquisa Agropecuária Brasileira, v.30, p.107-114, 1995.

COSTA, M.P. Efeito da matéria orgânica em alguns atributos do solo. Piracicaba, 1983. 137p. Dissertação (Mestrado) - Escola Superior de Agricultura "Luiz de Queiroz", Universidade de São Paulo.

DEMÉTRIO, R. Efeitos da aplicação de matéria orgânica sobre a biomassa - C microbiana do solo e o crescimento e absorção de nitrogênio em milho (Zea mays L.). Itaguaí, 1988. 98p. Dissertação (Mestrado) - Universidade Federal Rural do Rio de Janeiro.

EMPRESA BRASILEIRA DE PESQUISA AGROPECUÁRIA. Serviço Nacional de Levantamento e Conservação de Solos. Manual de métodos de análises de solos. Rio de Janeiro: EMBRAPA, SNLCS, 1979. 250p.

EMPRESA BRASILEIRA DE PESQUISA AGROPECUÁRIA. Serviço Nacional de Levantamento e Conservação do Solo. Critérios para distinção de classes de solo e de fases de unidades de mapeamento: normas em uso pelo SNLCS. Rio de Janeiro: EMBRAPA, SNLCS, 1988. 87p.

FERNANDES, M.R. Alterações em propriedades de um Latossolo Vermelho Distrófico, fase cerrado decorrentes da modalidade de uso e manejo. Viçosa, 1982. 65p. Dissertação (M.S.) Universidade Federal de Viçosa.

GOMES, F.P. Curso de estatística experimental. 12.ed. Piracicaba, Nobel; 1987. 467p.

NOVAIS, R.F. de; NEVES, J.C.; BARROS, N.F. Fósforo. In: FERTILIDADE e manejo do solo. Brasília: ABEAS, 1996. 133p. (Módulo, 7). 
RIBEIRO, A.C.; MELLO, J.W.V. de; NOVAIS, R. F. Propriedades físico-químicas do solo. In: FERTILIDADE e manejo do solo. Brasília: ABEAS, 1996. 54p. (Módulo, 3).

SALINAS, J.G.; GARCIA, R. Métodos químicos para el análises de suelos acidos y plantas forrajeras. Cali: CIAT,1985. 83p.

SERRÃO, E.A.S.; FALESI, I.C.; VEIGA, J.B.; TEIXEIRA, J.F. Productivity of cultivated pastures in low fertility soils of the Amazon of Brasil. In: SANCHEZ, P.A.; TERGAS, L.E. (Ed.) Pasture production in soils of the tropics. Cali: CIAT, 1979. p.195-226.

TEIXEIRA, L.B. Dinâmica do ecossistema de pastagem cultivada em área de floresta na Amazônica Central. Manaus, 1987. 100p. Tese (Doutorado) - Fundação Universidade do Amazonas.
VEIGA, J.B. da; SERRÃO, E.A.S.; PEDREIRA, C.A. Adubação de estabelecimento do capim andropogon (Andropogon gaianus Kunth) em área de pastagens degradadas de Paragominas. Belém: EMBRAPA, CPATU, 1985. 4p. (Comunicado Técnico, 57).

$\overline{\text { Recebido em } 18.02 .99}$ 